\title{
Study of Tubular Nickel Oxide Electrode
}

\author{
Ke He ${ }^{1,2}$, Jie Cheng ${ }^{2, *}$, Yuehua Wen ${ }^{2}$, Wenwen $\mathrm{Cai}^{1}$, Yusheng Yang ${ }^{1,2}$ \\ ${ }^{1}$ Zhangjiagang Smartgrid Fanghua Electrical Energy Storage Research Institute Co., Ltd, \\ Zhangjiagang, 215600, China \\ ${ }^{2}$ Research Institute of Chemical Defence, Beijing, 100191, China \\ email: chengjie_chj@126.com
}

Keywords: Flow battery, Zinc nickel single flow battery, Tubular nickel oxide electrode

\begin{abstract}
Tubular nickel oxide electrode was designed and tested in the paper. We successfully prepared a calandria by using polyamide filament, and successfully prepared a tubular nickel oxide electrode by using the tube and foamed nickel oxide electrode. Testing results of the tubular nickel oxide electrode used for zinc nickel single flow battery show good performance. Specific capacity of $35.7 \mathrm{mAh} / \mathrm{cm}^{2}$ (203 mAh/g), coulomb efficiency of 96.0\%, energy efficiency of $83.8 \%$ and cycle life of above 480 cycles are obtained. This indicates that the tubular nickel oxide electrode can be used in alkaline nickel-based batteries and reduce the costs of the nickel oxide electrodes.
\end{abstract}

\section{Introduction}

Renewable energy sources, such as wind power and solar energy power generation, have the characteristics of instability and discontinuity. Large-scale energy storage technology combined with renewable energy generation, energy storage unit playing an important role of "power bank", can smooth the waveform of renewable energy power generation, reduce the impact to the grid and give stable and continuous power supply [1,2]. Therefore, the research and development of large-scale energy storage device and the necessary technical equipment become a key link in electric energy sustainable development strategy; become an important part of national future energy strategy.

Zinc nickel single flow battery with high safety performance, environmentally friendly, long cycle life, wide range of application temperature, is a new kind of chemical power source suitable for large-scale energy storage system [3-6]. Now raising the battery capacity and cost reduction is at the heart of nickel anode materials. The core of the specific capacity increase and cost reduction of the battery is nickel anode electrodes for their high cost of manufacture. Foamed nickel electrodes have high filling amount of active materials, high energy density, low cost, but the cycle life in electrolyte flow is poor for the foamed nickel electrodes using in zinc nickel single flow battery. This study intends to break through the structure design, optimize the preparing process and reduce the costs of the nickel electrodes, to promote the development of zinc nickel single flow battery, and the progress of alkaline nickel-based batteries.

\section{Experimental}

Aim to hold the active materials from dropping off the surface of the electrode, tubular nickel oxide electrode was designed and prepared, as shown in Figure 1 schematically. The tubular construction minimizes both corrosion and shedding of current collectors, and long life is characteristic of these designs [7].

Tubular, with the pipe thickness of $0.6 \mathrm{~mm}$ and inner diameter of $5.0 \mathrm{~mm}$, was woven by nylon fiber. Slurry of nickel oxide was formed with a weight ratio of nickel oxide: nickel powder: CMC: PTFE $=88: 10: 1: 1$. The slurry was coated onto a piece of nickel foam sheet, and then the sheets were dried and pressed to form a foamed electrode. Half-cylinder with outside diameter of $5.0 \mathrm{~mm}$ of foamed nickel oxide electrode was preparing by using compression moulding forming. Two half-cylinders were combined into one cylinder and Inserted into the corresponding tubular. The 
tubular nickel oxide electrodes were then obtained. The working electrode contained about 610mg nickel oxide on an apparent area of $3.5 \mathrm{~cm}^{2}$.

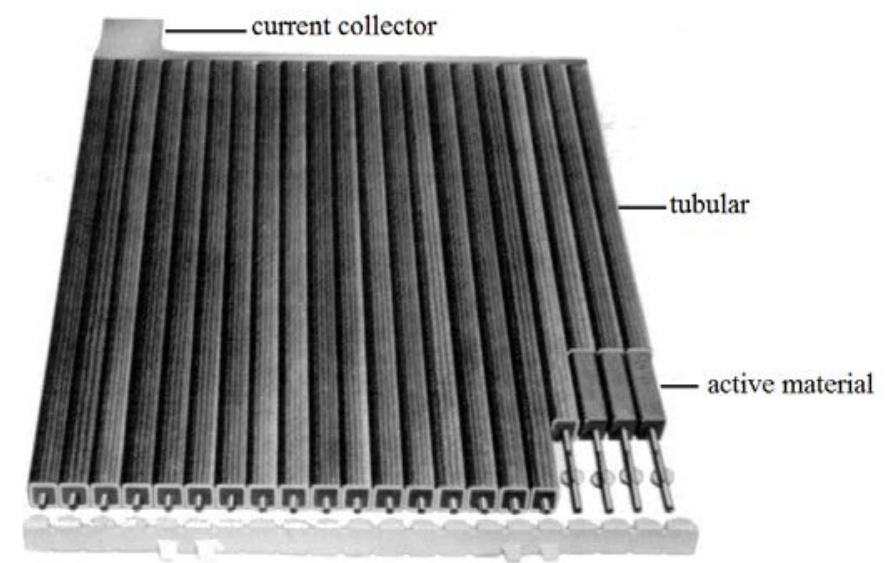

Figure 1 Schematic diagram of tubular nickel oxide electrode

The galvanostatic charge discharge tests were carried out in a two-electrode cell with a LAND CT2001A battery test system (Jinnuo Wuhan Corp., China) at an ambient temperature (about $25^{\circ} \mathrm{C}$ ). The experimental battery was constructed with the tubular nickel oxide electrode as the positive electrode and nickel-plated steel mesh as the negative electrode with an interelectrode gap of $5 \mathrm{~mm}$ [3]. The electrolytes used here are aqueous solutions of $1.0 \mathrm{~mol} / \mathrm{L} \mathrm{ZnO}$ in $10.0 \mathrm{~mol} / \mathrm{L} \mathrm{KOH}$. Reagent grade $\mathrm{KOH}$ and $\mathrm{ZnO}$ were used and the solution of $1.0 \mathrm{~mol} / \mathrm{L} \mathrm{ZnO}$ in $10.0 \mathrm{~mol} / \mathrm{L} \mathrm{KOH}$ medium was prepared using deionized water [3]. In unsaturated zincate solutions, the redox reaction occurring at the negative electrode is the deposition and dissolution of zinc [8], and the coulomb efficiency of the negative electrode is higher than that of nickel oxide electrode [3, 4]. So, the charge-discharge curves of the cell show the characteristics of the tubular nickel oxide electrode.

\section{Results and Discussion}

The zinc nickel single flow battery was charged to a capacity of $130 \mathrm{mAh}$ (or cut-off after the voltage up to $2.1 \mathrm{~V}$ ) and discharged to $1.2 \mathrm{~V}$ at the same current density of $100 \mathrm{~mA} / \mathrm{g}$ (based on the weight of $\left.\mathrm{Ni}(\mathrm{OH})_{2}\right)$, in which the apparent current density is about $17 \mathrm{~mA} / \mathrm{cm}^{2}$.

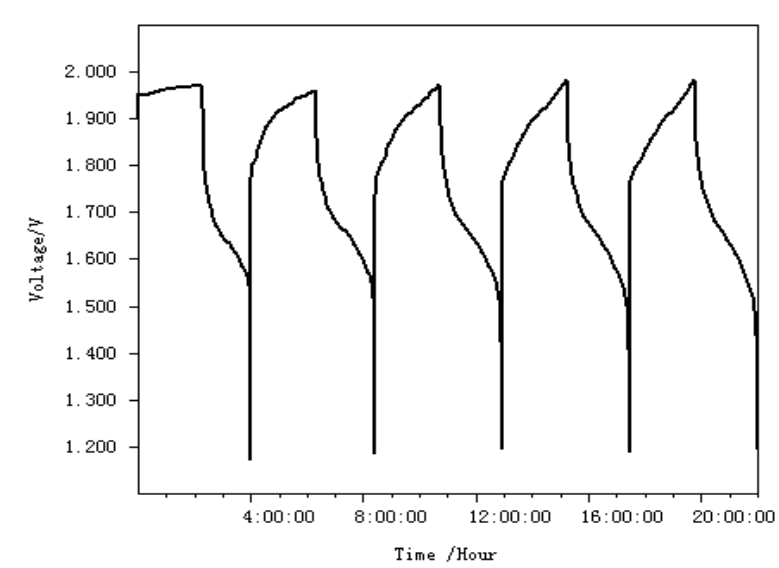

(a) First five cycles

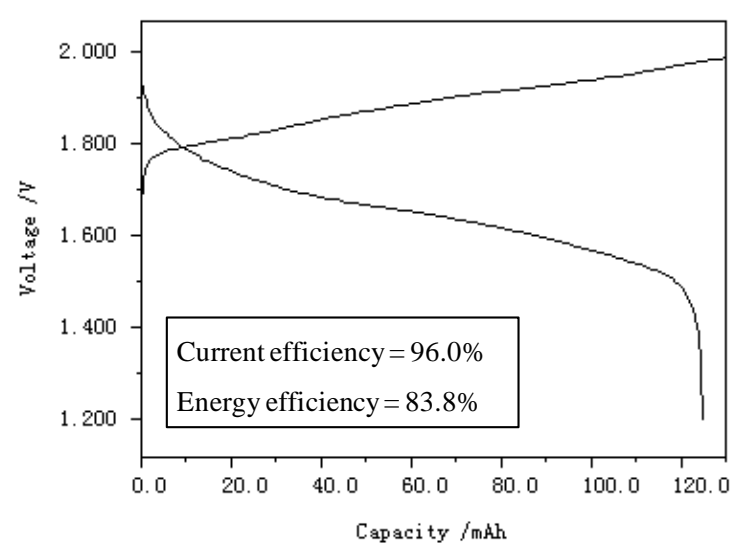

(b) sixth cycle

Figure 2 Charge discharge curves of the zinc nickel single flow battery (at $100 \mathrm{~mA} / \mathrm{g}$ )

The charge discharge curves of the zinc nickel single flow battery are shown in Figure 2. The cell voltage changed drastically at the start of charge and at the end period of discharge. This indicated that the polarization of the cell was very large [3]. In Figure 2a, the charge voltage increase sharply to $2.0 \mathrm{~V}$ at first charge, and the coulomb efficiency of first cycle is about $72.2 \%$. 
The charge voltage of the second charge does not increase sharply, and coulomb efficiency increase to $90.4 \%$. This indicates an activation process occurring on the tubular nickel oxide electrode. After initial activation cycle, the performance of the battery becomes stable. In Figure $2 \mathrm{~b}$, the coulomb efficiency and energy efficiency are about $96.0 \%$ and $83.3 \%$, the average charge voltage and discharge voltage are about $1.89 \mathrm{~V}$ and $1.65 \mathrm{~V}$, respectively. The average discharge voltage is almost the same with that of the sintered nickel electrode reported in the literature [3], and the discharge capacity of tubular nickel oxide electrode achieves $35.7 \mathrm{mAh} / \mathrm{cm}^{2}$ (124 mAh, $203 \mathrm{mAh} / \mathrm{g}$ based on the weight of $\left.\mathrm{Ni}(\mathrm{OH})_{2}\right)$, higher than that of sintered nickel electrode [9].

The zinc nickel single flow battery was cycled at the current density of $100 \mathrm{~mA} / \mathrm{g}$, the cells show a more stable cycle life, and the recession curves with cycles are shown in Figure 3. After 480 cycles, the discharge capacity of the cells still keeps about $82 \%$ of the maximum discharge capacity. This results demonstrate that the tubular nickel oxide electrode is promising as a substitute for the sintered nickel oxide electrode.

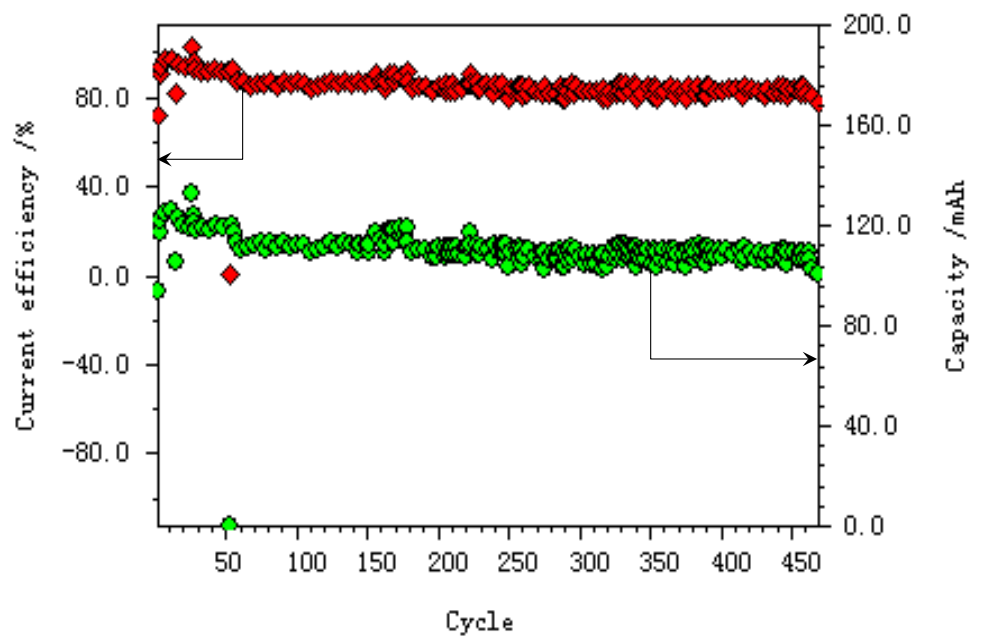

Figure 3 Recession curves with cycles of the zinc nickel single flow battery (at $100 \mathrm{~mA} / \mathrm{g}$ )

By contrast, foamed nickel oxide electrodes are also tested for the zinc nickel single flow battery. The results show a very poor cycle life of about 10 cycles. Therefore, the above results demonstrate that the tubular nickel oxide electrode for the alkaline batteries is feasible and worthy of further investigation.

\section{Conclusion}

Tubular nickel oxide electrode was successfully produced with nylon fibers based on preparation process of foamed nickel oxide electrode. The zinc nickel single flow battery based on tubular nickel oxide electrode was tested at charge and discharge current density of $100 \mathrm{~mA} / \mathrm{g}$ (based on the weight of $\left.\mathrm{Ni}(\mathrm{OH})_{2}\right)$. The average charge voltage and discharge voltage are about $1.89 \mathrm{~V}$ and $1.65 \mathrm{~V}$, respectively. After 480 cycles, the discharge capacity of the cells still keeps about $82 \%$ of the maximum discharge capacity. This results demonstrate that the tubular nickel oxide electrode for the alkaline batteries is feasible and worthy of further investigation.

\section{Acknowledgement}

Technique support of tubular preparation from Zhangjiagang Junshang Textile Technology Cooperation Limited is gratefully acknowledged.

\section{References}

[1] Marion Perrin, Philippe Malbranche, Elisabeth Lemaire-Potteau, B. Willer, M.L. Soria, A. Jossen, M. Dahlen, A. Ruddell, I. Cyphelly, G. Semrau, D.U. Sauer, G. Sarre. Temperature 
behaviour: Comparison for nine storage technologies Results from the INVESTIRE Network, Journal of Power Sources, 154: 545-549, 2006

[2] C. Ponce de León, A. Frías-Ferrer, J. González-García, D.A. Szánto, F.C. Walsh. Redox flow cells for energy conversion. Journal of Power Sources, 160: 716-732, 2006

[3] Jie Cheng, Li Zhang, Yu-sheng Yang, Yue-hua Wen, Gao-ping Cao, Xin-dong Wang. Preliminary study of single flow zinc-nickel battery, Electrochemistry Communications, 9: 2639-2642, 2007

[4] Li Zhang, Jie Cheng, Yu-sheng Yang, Yue-hua Wen, Xin-dong Wang, Gao-ping Cao. Study of zinc electrodes for single flow Zinc/nickel battery application, Journal Power Sources, 179: 381-387, 2008

[5]Jie Cheng, Yue-Hua Wen, Gao-Ping Cao, Yu-Sheng Yang. Influence of zinc ions in electrolytes on the stability of nickel oxide electrodes for single flow zinc-nickel batteries, Journal Power Source, 196: 1589-1592, 2011

[6]Dong Chen, Jie Cheng, Yuehua Wen, Junqing Pan, Gaoping Cao, Yusheng Yang. Preparation and the Electrochemical Properties of Monolithic Porous Carbon as a Substrate for Nickel Hydroxide Electrode, Journal of The Electrochemical Society, 158(12): A1303-A1306, 2011

[7] David Linden, Thomas B. Reddy. Handbook of batteries (3rd edition). The McGraw-Hill Companies, Inc., 2001

[8] Sayed S. Abd El Rehim, E.E. Foad El-Sherbini, Mohammed A. Amin. Pitting corrosion of zinc in alkaline medium by thiocyanate ions, Journal of Electroanalytical Chemistry 560: 175-182, 2003

[9]W. K. Zhang, X. H. Xia, H. Huanga, Y. P. Gan, J. B. Wu, J. P. Tu. High-rate discharge properties of nickel hydroxide/carbon composite as positive electrode for $\mathrm{Ni} / \mathrm{MH}$ batteries, Journal Power Source, 184: 646-651, 2008 